\title{
Transcriptomic Profiling of Human Placental Trophoblasts in Response to Infection with Enterococcus faecalis
}

\author{
Qianglai Tan, ${ }^{1,2}$ Feng Xu, ${ }^{2}$ Hengyi Xu, ${ }^{2}$ Liang Qiu, ${ }^{2}$ Xueying Tao, ${ }^{2}$ and Hua Wei ${ }^{2}$ \\ ${ }^{1}$ Institute of Nutrition and Food Safety, Xiamen Medical College, Xiamen, Fujian 361023, China \\ ${ }^{2}$ State Key Laboratory of Food Science and Technology, Nanchang University, Nanchang, Jiangxi 330047, China \\ Correspondence should be addressed to Hua Wei; weihua@ncu.edu.cn
}

Received 23 October 2017; Revised 19 December 2017; Accepted 9 January 2018; Published 27 February 2018

Academic Editor: Ángel A. Carbonell-Barrachina

Copyright (C) 2018 Qianglai Tan et al. This is an open access article distributed under the Creative Commons Attribution License, which permits unrestricted use, distribution, and reproduction in any medium, provided the original work is properly cited.

\begin{abstract}
Increasing evidence suggests that Enterococcus faecalis strains can pass through placental barriers and cause adverse outcomes during pregnancy. However, the underlying molecular mechanism of the interaction between E. faecalis and the host placental barrier has yet to be fully elucidated. In this study, we have used DNA microarray analysis to investigate the response of human placental trophoblast-like BeWo cells to infection with E. faecalis OG1RF. These results indicate that a total of 2191 genes in BeWo cells are differentially expressed in the presence of E. faecalis OG1RF, with 1357 genes being upregulated and 834 genes being downregulated. These differentially expressed genes (DEGs) are involved in apoptosis, stress and stimulus response, placental and embryonic development, immune response, and cell adhesion. Therefore, these results provide information on the molecular mechanisms that $E$. faecalis invasion can trigger to cause adverse pregnancy outcomes.
\end{abstract}

\section{Introduction}

Enterococcus faecalis is a ubiquitous gram-positive bacterium that occurs widely in the foods, alimentary tract, and vagina [1], with certain E. faecalis strains regarded as commensal bacteria [2]. However, E. faecalis can readily cross host barriers, causing various nosocomial infections and diseases, including bacteremia and sepsis [3-6]. We have shown that E. faecalis OG1RF can cross the placental barriers of pregnant mice and translocate into the fetus [6]. Hence, food-borne E. faecalis may affect the quality and security of food, which has potentially serious implications for pregnant women. Many recent studies have focused on safety assessment of $E$. faecalis isolates from foods $[7,8]$. However, knowledge of the molecular mechanisms that E. faecalis employs to traverse the host placental barrier remains unclear. The changes in gene expression of human placental trophoblasts are likely to investigate the effects of $E$. faecalis infection on maternal and fetal health.

Transcriptomic profiling has been widely applied for studying the molecular mechanisms underpinning bacteriahost interactions. Fan et al. have employed a purpose built
Bam $4 \mathrm{kOLI}$ microarray to carry out transcriptome analysis of Bacillus amyloliquefaciens FZB42 in response to exposure to maize root exudates [9]. In addition, Chessler et al. have used DNA microarrays to show that Trypanosoma cruzi triggers an early type I IFN response in vivo at the site of intradermal infection [10].

The BeWo cell line has been shown to be a useful in vitro placental barrier model for studying adhesion, transport, and infection [11], with many researchers using BeWo cells as an in vitro barrier model of the placenta to explore the transport and toxicity of foreign agents or organisms $[12,13]$.

Food-borne E. faecalis was shown to cross host intestinal and placental barriers, thus affecting fetal and placental growth and development [6]. Consequently, we used BeWo cell to develop an in vitro placental barrier model to investigate the interaction, adhesion, and translocation of E. faecalis OG1RF in the placenta. In this study, we have used DNA microarrays to investigate the molecular mechanisms that $E$. faecalis OGIRF triggers in BeWo cells that can potentially cause adverse pregnancy outcomes. These include the differential expression of many genes involved in apoptosis, stress response, placental and embryonic development, immune 
response, and cell adhesion in BeWo cells. Therefore, this study may contribute to understand and control the effects of food-borne E. faecalis on food quality and security.

\section{Materials and Methods}

2.1. BeWo Cell Line and Cell Culture. Human choriocarcinoma cell line BeWo was purchased from Action-award Biotech Co., Ltd (Guangzhou, China). BeWo cells were cultured in DMEM/F12 medium supplemented with $10 \%(\mathrm{v} / \mathrm{v})$ FBS (Gibco, Grand Island, NY) and grown in $25 \mathrm{~mm}^{2}$ cell culture flasks (NEST, Jiangsu, China) at $37^{\circ} \mathrm{C}$ under a $5 \% \mathrm{CO}_{2}$ atmosphere, until approximately $80-90 \%$ cell confluence (as verified by inverted light microscopy). BeWo cells were then liberated from cell culture flasks using $0.25 \%$ trypsin-EDTA (Solarbio, Beijing, China), before being resuspended in fresh medium containing $10 \% \mathrm{FBS}$, and then transferred to new flasks.

\subsection{Bacterial Strain and Culture Condition. E. faecalis} OG1RF (ATCC ${ }^{\circledR} 47077^{\mathrm{TM}}$ ) was cultured in trypticase soy broth (TSB) at $37^{\circ} \mathrm{C}$ for $24 \mathrm{~h}$ with shaking at $180 \mathrm{rpm}$. The bacteria were harvested by centrifugation at 6,000 rpm for $10 \mathrm{~min}$, washed twice with sterile PBS $(0.01 \mathrm{M}, \mathrm{pH} 7.4)$, and reconstituted in cell culture medium DMEM/F-12 (Solarbio, Beijing, China) to give a concentration of $10^{9} \mathrm{CFU} / \mathrm{mL}$ before use.

2.3. Invasion Assays. For invasion experiments, the liberated BeWo cells were transferred into 24-well plates (Corning, $\mathrm{NY}$ ) and cultured for $48 \mathrm{~h}$ until a confluent monolayer was obtained. Culture supernatant was then removed and $5 \mu \mathrm{L}$ of resuspended bacteria added to each well containing $495 \mu \mathrm{L}$ DMEM/F12/10\% FBS, with incubation then carried out under an atmosphere of $5 \% \mathrm{CO}_{2}$ at $37^{\circ} \mathrm{C}$ for 60 minutes.

The total number of invaded bacteria associated with BeWo cells (including adherent and internalized E. faecalis) was determined by twice dip-washing with sterile PBS to remove free bacteria, followed by lysis of BeWo cells using $500 \mu \mathrm{L} 0.5 \%$ Triton X-100/PBS to release internalized bacteria [14]. Serial dilutions were then carried out to afford suspensions that were spread onto TSA plates and incubated at $37^{\circ} \mathrm{C}$ overnight to quantify the number of bacteria present.

The numbers of internalized bacteria present were determined using minor modifications of an antibiotic survival assay that has been described previously [15]. Therefore, bacteria and BeWo cells were incubated together for $60 \mathrm{~min}$, unbound bacteria were washed away, and then $500 \mu \mathrm{L}$ of DMEM/F12/10\% FBS supplement containing $100 \mu \mathrm{g} / \mathrm{mL}$ gentamicin and $50 \mu \mathrm{g} / \mathrm{mL}$ penicillin was added. Bacteria and BeWo cells were then incubated for $60 \mathrm{~min}$ to kill any viable extracellular bacteria still present; then cells were washed twice and lysed, and the bacterial count was determined as described above.

2.4. RNA Preparation, DNA Microarray, and Data Analysis. BeWo cells were incubated in fresh medium for $4 \mathrm{~h}$, with or without $E$. faecalis OG1RF before their total RNA was extracted using TRNzol Total RNA Reagent (Catalog number
DP405-02, TIANGEN, Beijing, China). RNA quality was assessed using an Agilent 2100 bioanalyzer (Agilent Technologies, CA).

Beijing EMTD Technology Development Co. Ltd. carried out all microarray analysis using Illumina Human HT-12 v4 Expression BeadChip microarrays (Illumina, Inc., San Diego, CA). RNA preparation and hybridization were performed according to the manufacturer's instructions [16], with data assessed using a Bead-array Reader and permutMatrix1.9.3EN. Illumina expression data was deposited in the NCBI Gene Expression Omnibus (GEO) database under the accession number GSE75626. Differential expression genes were analyzed using Gene Ontology (GO) and Kyoto Encyclopedia of Genes and Genomes (KEGG) pathway databases.

2.5. Real-Time Fluorescent Quantitative PCR. First strand cDNA was synthesized using a Quantscript RT Kit Quant cDNA first strand Synthesis Kit (TIANGEN, Beijing, China). Real-time PCR was carried out using a SYBR ${ }^{\circledR}$ Premix Ex $\mathrm{Taq}^{\text {тм }}$ II (Tli RNaseH Plus) Kit (TaKaRa, Dalian, China) using the primer sets listed in Table 3. Amplification and detection were carried out using a 7900HT Fast Real-Time PCR System (Applied Biosystems, Foster City, CA). The realtime PCR conditions employed were as follows: 1 cycle at $95^{\circ} \mathrm{C}$ for $2 \mathrm{~min}, 45 \mathrm{cycles}$ at $95^{\circ} \mathrm{C}$ for $20 \mathrm{~s}$, heating at $60^{\circ} \mathrm{C}$ for $30 \mathrm{~s}$, and heating at $68^{\circ} \mathrm{C}$ for $30 \mathrm{~s}$. Melt curve analysis was carried out by heating samples for $1 \mathrm{~min}$ at $95^{\circ} \mathrm{C}$ and cooling to $55^{\circ} \mathrm{C}$, followed by slow heating to $95^{\circ} \mathrm{C}$ whilst measuring any changes in fluorescence. Relative mRNA levels were determined using comparative critical threshold $(\mathrm{Ct})$ realtime PCR (separate tube) analysis, as described in Applied Biosystems User Bulletin number 2 (P/N 4303859).

2.6. Statistical Analysis. Unless specified, all experiments were performed in triplicate. All data was analyzed using statistics programs contained in SigmaPlot 11.0 (Systat Software, San Jose, CA).

\section{Results}

3.1. Invasion Ability of E. faecalis. The number of E. faecalis OG1RF strain present in BeWo cells was determined using invasion assays. As shown in Figure 1, the total number of invaded bacteria was $6.32 \pm 0.10 \log _{10} \mathrm{CFU} / \mathrm{mL}$ (including adherent and internalized E. faecalis OG1RF), with a total cell count for internalized bacteria of $2.23 \pm 0.29 \log _{10}$ $\mathrm{CFU} / \mathrm{mL}$. This assay confirmed that E. faecalis OG1RF can invade BeWo cells, suggesting that this species can readily cross the placental barrier, in accord with our previous study [6].

3.2. Differential Gene Expression Profile Analysis. DNA microarray techniques were used to compare the gene expression patterns of untreated BeWo cells with those infected by E. faecalis. After applying cut-off limits for induction (ratio > 2.0 -fold) and suppression (ratio $<0.5$-fold), 2191 genes (out of a total 47,231 genes) were found to be differentially expressed in the presence of E. faecalis. This included 1357 genes that had 


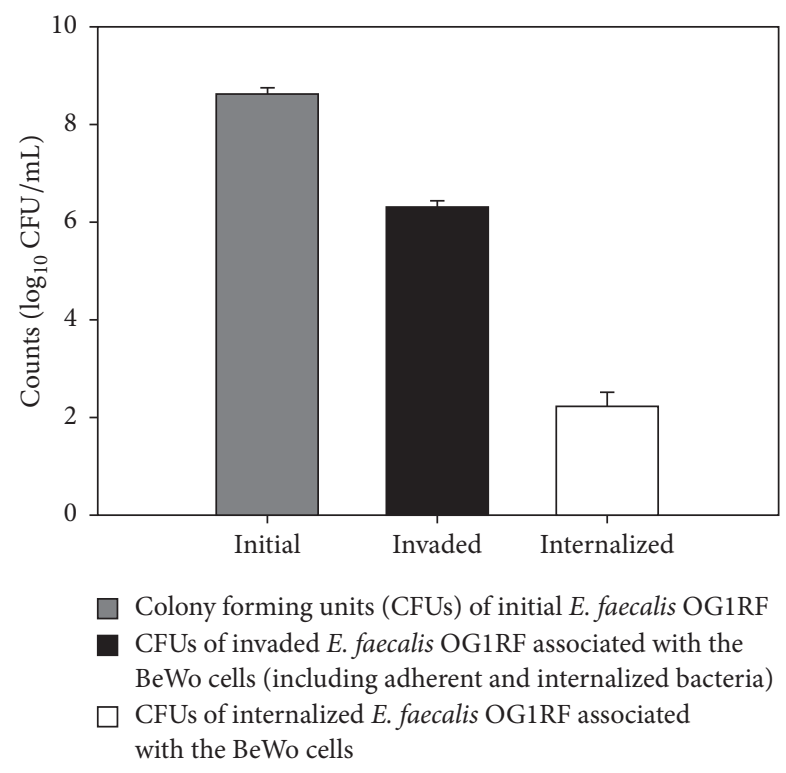

FIGURE 1: Invasion assay of the human choriocarcinoma cell line BeWo with Enterococcus faecalis OG1RF. Values represent mean \pm SD.

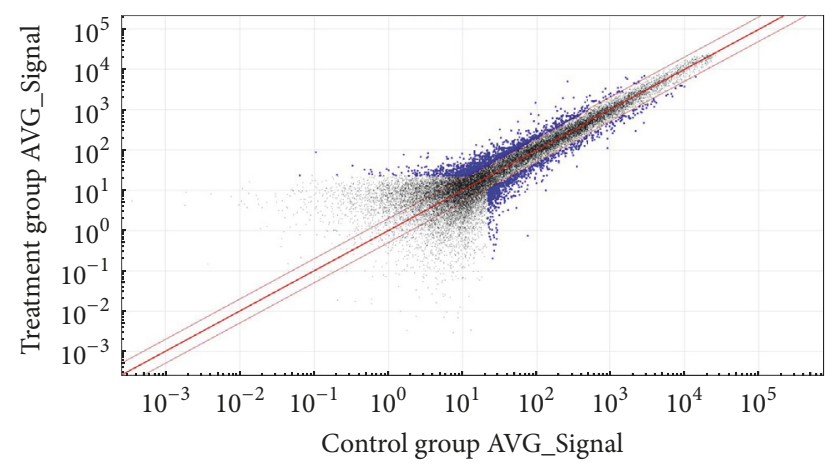

FIGURE 2: Logarithmic scatter plot of DEGs of treatment group. DEGs are represented by blue dots and non-DEGs by black dots. Upregulated and downregulated genes are segmented by a red slash. Treated group: BeWo cells were incubated in fresh medium for $4 \mathrm{~h}$ with $E$. faecalis OG1RF.

been upregulated and 834 genes that had been downregulated (Figure 2 and Table S1).

3.3. Bioinformatic Analysis of DEGs. The function of the DEGs that were affected by $E$. faecalis infection were characterized by comparison against the GO database which enabled their biological function to be identified. These results showed that 338 terms were responsible for "biological processes," 59 terms were responsible for "cellular component," and 68 terms were involved in "molecular function" (Tables S2-4). Most of the genes identified were classified under GO biological process categories using the terms "cellular process," "regulation of cellular process," "metabolic process," "regulation of metabolic process," "biosynthetic process," "regulation of biosynthetic process," "gene expression," "regulation of gene expression," "transcription," and "regulation of transcription" (Figure 3 and Table S5).

Of relevance to this study, 45 DEGs associated with placenta and embryonic development were identified, namely, "chordate embryonic development," "embryonic development ending in birth or egg hatching," "in utero embryonic development," "placenta development," and "embryonic placenta development" (Figure 3, Table 1 and Table S5). These results provide clues to the molecular mechanisms that $E$. faecalis OG1RF can employ to stunt placental and fetal growth and development [6]. Furthermore, other DEGs were categorized as being involved in cell adhesion, including "cytoskeleton organization," "actin cytoskeleton organization," "actin filament organization," "negative regulation of cell adhesion," "negative regulation of cell-substrate adhesion," "negative regulation of cell-matrix adhesion," and "negative regulation of intracellular transport." These results agree with those of Peng et al., who have also reported on the range of molecular mechanisms employed by bacteria to cross the barrier [1]. Furthermore, we identified many other DEGs that are involved in "immune response," "apoptosis," and "stress and stimulus response" (Figure 3, Table 1 and Table S5). Being combined, these results indicate that $E$. faecalis infection can cause stress responses that stimulate host immune defense systems and induce cell apoptosis.

3.4. Signal Pathway Analysis of DEGs. DEGs were then mapped using the KEGG database for signal pathway analysis to gain further understanding of their biological function. These results reveal that these DEGs could be further categorized using 31 terms used by the KEGG database (Table S6). Close analysis revealed 13 main terms associated with differential gene expression of BeWo cells in response to E. faecalis invasion, namely, "Wnt signaling pathway," "Jak-STAT signaling pathway," "MAPK signaling pathway," "mTOR signaling pathway," "focal adhesion," "regulation of actin cytoskeleton," "adherens junction," "pathogenic Escherichia coli infection," "T cell receptor signaling pathway," "B cell receptor signaling pathway," "Toll-like receptor signaling pathway," "apoptosis," and "p53 signaling pathway" (Table 2).

According to descriptions used in the KEGG database (http://www.genome.jp), these descriptors are associated with the following biological processes. Activation of Wnt for basic developmental processes, such as embryonic and placental development [17]. The Jak-STAT pathway is the principal signaling mechanism for regulating cytokines and growth factors. Regulation of MAPK is important in cell proliferation, differentiation, and migration, which can be activated by diverse stimuli such as pathogen-associated molecular patterns and environmental stresses [18]. The mTOR pathway is a key intracellular signaling pathway that regulates the cell cycle that can respond to the presence of nutrients and mitogens. Focal adhesions are comprised of bundles of actin filaments anchored to transmembrane receptors that serve to connect membrane receptors to the actin cytoskeleton. Adherent junctions are the most common type of intercellular adhesions that are responsible for maintaining 


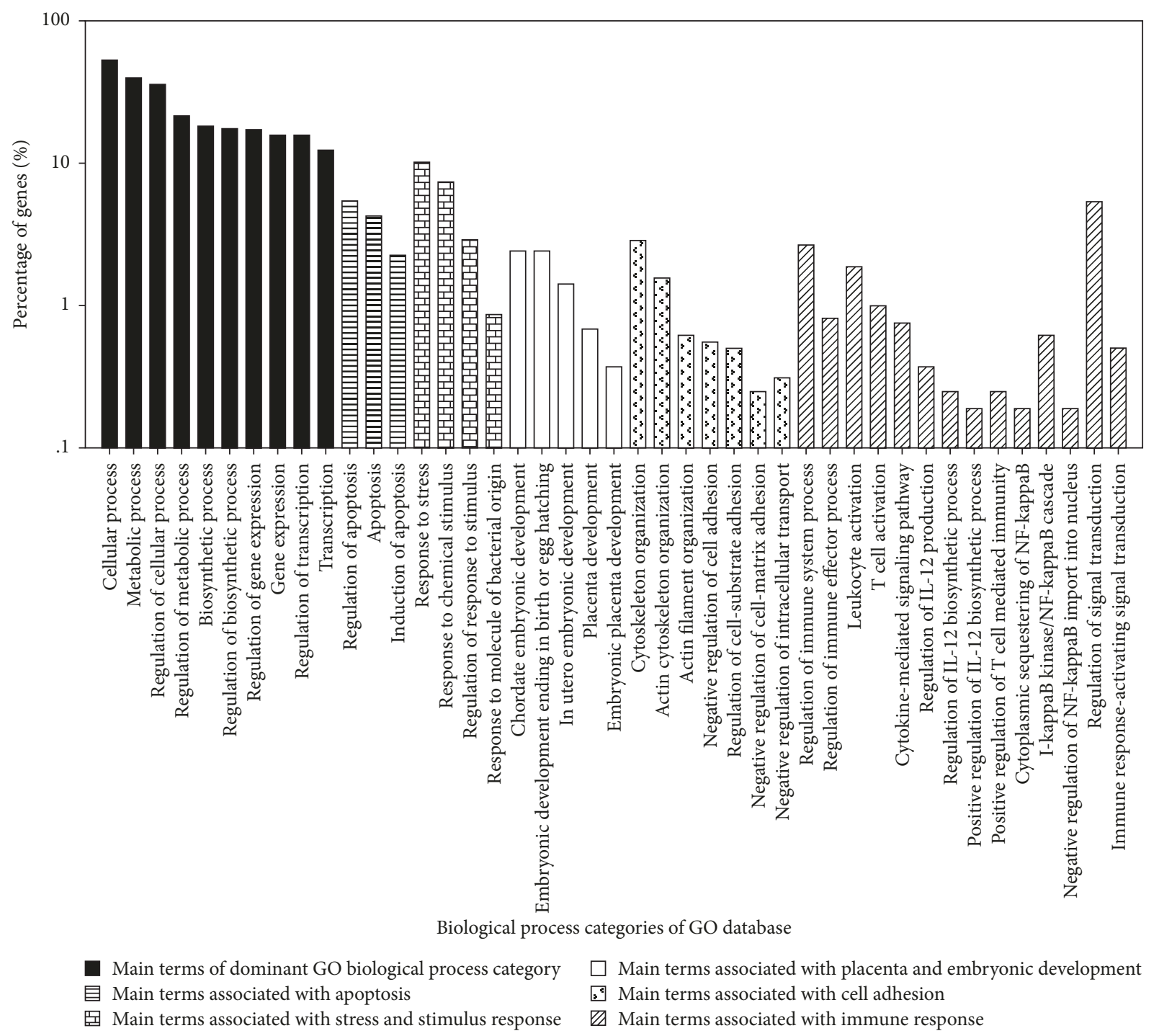

FIGURE 3: Histogram presentation of representative terms of GO biological process category. The $y$-axis indicates percentage of genes in GO biological process category.

the integrity of tissue architecture. Activation of T and B cell receptors is necessary for an efficient immune response to occur, whilst Toll-like receptors are responsible for detecting pathogens and triggering an innate immune response. p53 is known to be induced by stress signals, which can result in genetically controlled cell death.

Importantly, these KEGG analysis results were largely in accord with results obtained from bioinformatic analyses (Figure 3, Table 1, and Table S5), thus providing an insight into the molecular events that occur when E. faecalis invades host placental cells.

3.5. Real-Time PCR Analysis. Changes to the transcriptional level of selected genes were studied using real-time PCR. As shown in Figure 4, the expression levels of IL1, IL8, and TNF$\alpha$ were significantly upregulated, whilst IL4, IL6, IL10, IL12, and IFN- $\gamma$ were significantly downregulated, thus providing further indication that infection with E. faecalis perturbs the host immune defense systems. Furthermore, expression of TLR1, 2, 3, 4, and 6 was significantly downregulated, suggesting that the host's ability to tackle this pathogen was being suppressed. Meanwhile, expression of claudin 1, E-cadherin, occludin, ZO-1, ICAM, and madCAM was significantly downregulated, indicating that infection with $E$. faecalis also results in disruption of the placental barrier.

\section{Discussion}

Previously, we have shown that E. faecalis can cross the placental barrier, resulting in fetal and placental growth and development being stunted [6]. However, little is known about the molecular mechanisms that occur during bacterialhost interactions that result in fetoplacental tropism. Hence, we have employed DNA microarray techniques to identify 


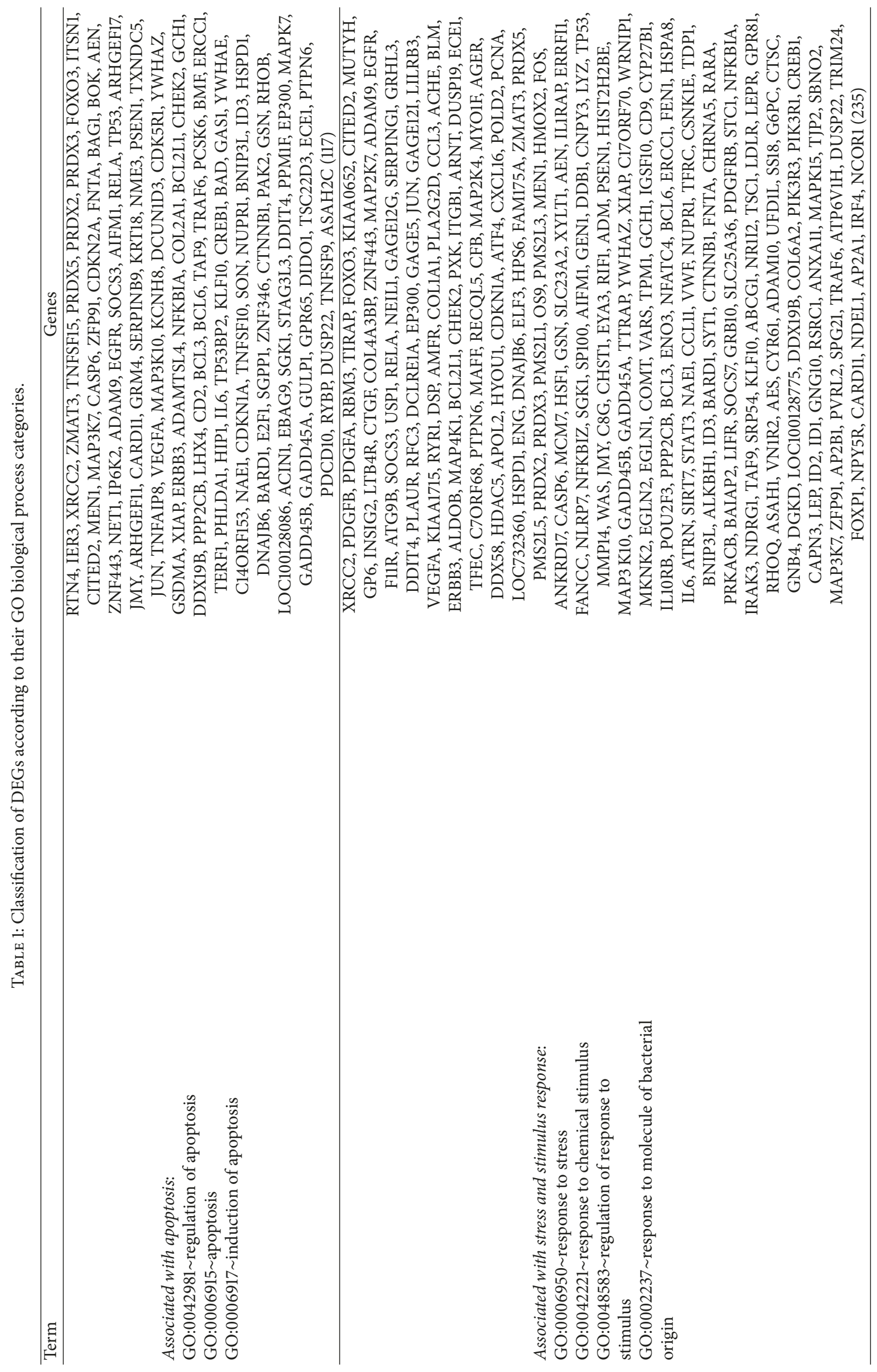




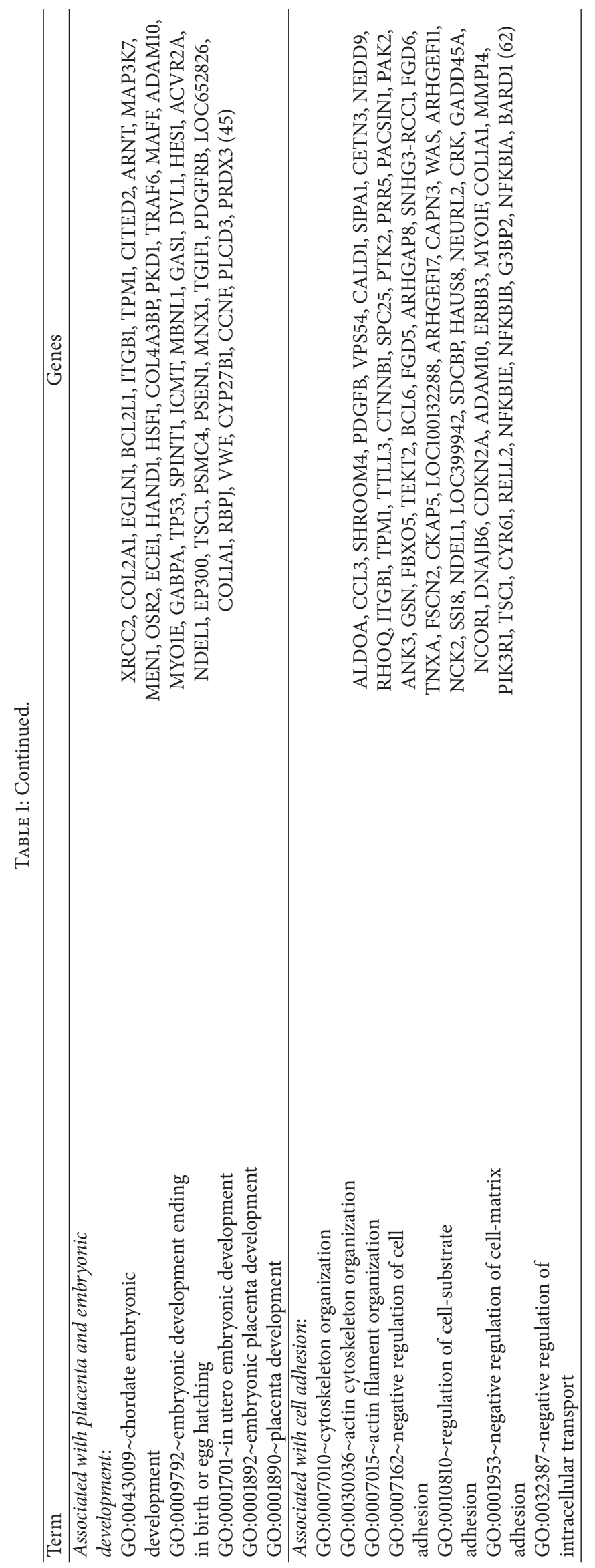




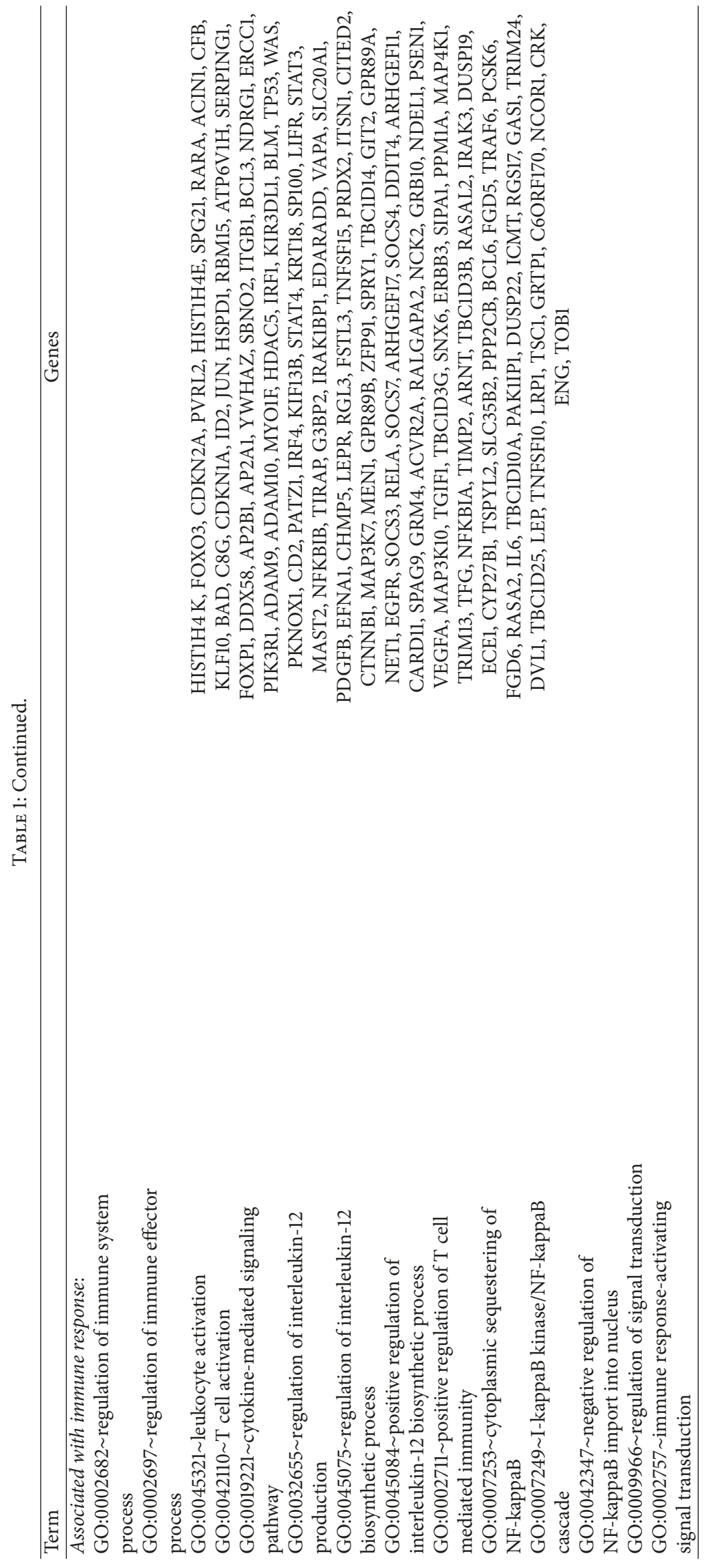




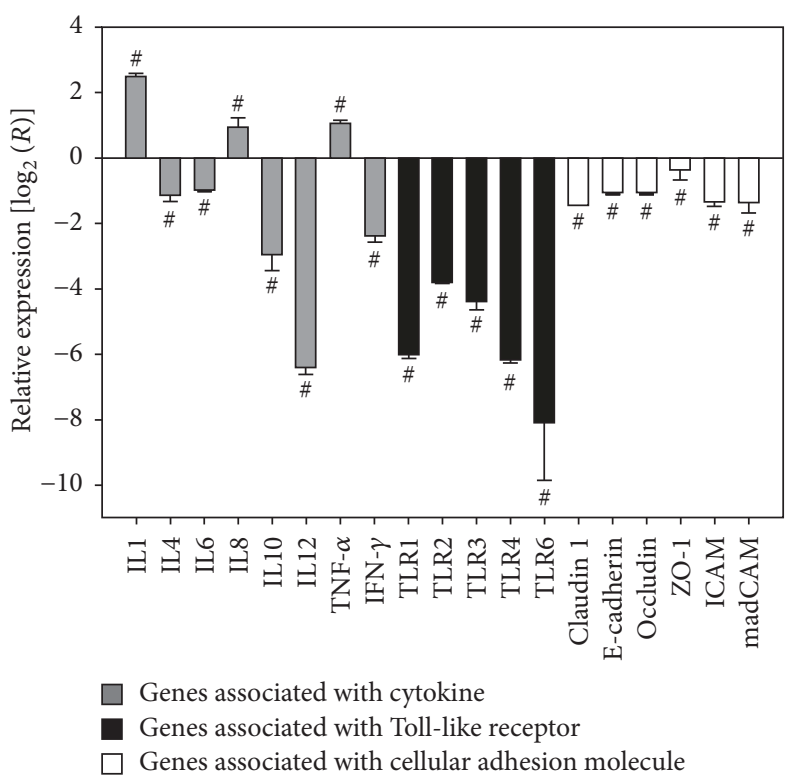

FIGURE 4: Fold-change of DEGs selected for validation by real-time PCR. The housekeeping gene $\beta$-2-microglobulin was used to normalize input amounts of RNA and the levels of gene expression between coincubation samples and individual bacteria compared. The relative expression ratio for each gene is presented as $\log _{2}$ value in the histogram. A ratio greater than zero $(>0)$ indicates upregulation of gene expression and a ratio lower than zero $(<0)$ indicates downregulation. Error bars represent the standard deviations from triplicate analysis of each sample.

${ }^{\#}$ Significant difference $(p<0.05)$. Values represent mean \pm SD.

differential gene expression in placental trophoblasts in response to E. faecalis invasion. Whole-genome expression using BeadChip has been used to investigate differential gene expression of cells in response to infection, disease, and environmental stress [19]. In comparison with realtime PCR, the BeadChip technique can rapidly analyze microdoses in parallel using automated high throughput systems. Consequently, we employed the Illumina Human HT-12 v4 Expression BeadChip to investigate the biological effects that occur when placental cells are infected with $E$. faecalis.

According to the DNA microarray results, 45 DEGs were associated with placenta and embryonic development, which belonged to 5 terms within the GO "biological process" category. It is proposed that these changes to gene expression in placental trophoblasts in response to E. faecalis infection are likely to have a negative effect on placental and fetal health. This is in accord with our previous study, which found that $E$. faecalis infection resulted in a reduction in placental and fetal weights in vivo [6]. Furthermore, KEGG analysis revealed that exposure to E. faecalis resulted in DEGs that could affect numerous other biological pathways in placental trophoblasts. Among the KEGG annotated sequences, 18 genes were classified as being part of the Wnt signaling pathway, which is involved in multiple developmental events during embryogenesis $[17,20]$. Indeed, Li et al. have previously shown that many of the genes involved in embryonic development that exhibit high ingenuity pathway analysis scores are responsible for cell death, which can lead to reduced fetal and placental weights in pregnant rats [21].
Other genes were identified, which control three signaling pathways involved in "focal adhesion," "regulation of actin cytoskeleton," and "adherens junction." These pathways are associated with changes to the cell-extracellular matrix, cellcell adhesion properties, and the maintenance of normal cellular structure and function (Table 2). Meanwhile, 62 genes were identified with cell adhesion-related terms relating to GO "biological process" categories (Table 1) that are likely to play important roles in maintaining the integrity of the placental barrier $[22,23]$. Hence, the differential expression of these genes is likely to impair the normal structure and function of placental barrier, thus contributing to $E$. faecalis invasion and fetoplacental tropism. In this respect, a previous study by Peng et al. has revealed that $E$. faecalis enables actin to pass through the intestinal barrier [1]. Moreover, E. faecalis can also trigger the loss of E-cadherin, leading to impairment of intestinal and placental barriers $[5,6]$. Interestingly, Listeria monocytogenes is a closely related pathogen that is also known to cross human intestinal and placental barriers via adhesion to E-cadherin [15, 24-26].

Large numbers of DEGs and signaling pathways that are closely related to the immune system response were also affected. Whilst changes in gene expression may activate or suppress host immune defense systems, disruption of the immune system in pregnancy can cause trophoblast death, resulting in placental insufficiency, spontaneous abortion, preterm labor, or stillbirth $[27,28]$. In addition, many DEGs were identified, which are known to be involved in apoptosis, which could potentially cause preeclampsia, or intrauterine growth retardation [29]. Similarly, Trypanosoma cruzi has 
TABLE 2: DEGs associated with signal pathways assigned by KEGG pathway analysis.

\begin{tabular}{|c|c|c|c|}
\hline No. & Term & Count & Genes \\
\hline 1 & $\begin{array}{l}\text { hsa04310:Wnt signaling } \\
\text { pathway }\end{array}$ & 18 & $\begin{array}{l}\text { CTBP1, CTBP2, TP53, CTNNB1, DVL1, MAP3K7, EP300, } \\
\text { PSEN1, PRICKLE1, CSNK1E, JUN, PPP2CB, NFAT5, FRAT1, } \\
\text { CAMK2B, NFATC4, PRKACB, NFATC1 }\end{array}$ \\
\hline 2 & $\begin{array}{l}\text { hsa04010:MAPK signaling } \\
\text { pathway }\end{array}$ & 31 & $\begin{array}{c}\text { FGFR4, PDGFB, PDGFA, PPM1A, MKNK2, MAP4K1, PPM1B, } \\
\text { NFKB2, MAP3K7, MAX, FOS, PAK2, PLA2G12A, NFATC4, } \\
\text { PRKACB, TRAF6, MAP2K7, HSPA8, RASA2, EGFR, RELA, } \\
\text { MAP2K4, TP53, ATF4, JUN, PDGFRB, MAPK7, GADD45B, } \\
\text { CRK, PLA2G2D, GADD45A }\end{array}$ \\
\hline 3 & $\begin{array}{l}\text { hsa04662:B cell receptor } \\
\text { signaling pathway }\end{array}$ & 15 & $\begin{array}{l}\text { PTPN6, IFITM1, NFKBIE, RELA, NFKBIB, NFKBIA, FOS, } \\
\text { CARD11, LILRB3, JUN, NFAT5, NFATC4, PIK3R3, PIK3R1, } \\
\text { NFATC1 }\end{array}$ \\
\hline 4 & $\begin{array}{l}\text { hsa04660:T cell receptor } \\
\text { signaling pathway }\end{array}$ & 18 & $\begin{array}{l}\text { PTPN6, NFKBIE, RELA, NFKBIB, NFKBIA, MAP3K7, FOS, } \\
\text { NCK2, CARD11, PAK2, JUN, PAK4, NFAT5, NFATC4, PIK3R3, } \\
\text { MAP2K7, PIK3R1, NFATC1 }\end{array}$ \\
\hline 5 & $\begin{array}{l}\text { hsa04620:Toll-like receptor } \\
\text { signaling pathway }\end{array}$ & 13 & $\begin{array}{c}\text { CCL3, IL6, RELA, MAP2K4, TIRAP, NFKBIA, MAP3K7, FOS, } \\
\text { JUN, PIK3R3, TRAF6, MAP2K7, PIK3R1 }\end{array}$ \\
\hline 6 & $\begin{array}{l}\text { hsa04630:Jak-STAT } \\
\text { signaling pathway }\end{array}$ & 20 & $\begin{array}{c}\text { PTPN6, IL6, SOCS3, LEPR, LIFR, SOCS7, SOCS4, BCL2L1, } \\
\text { STAT3, LEP, ZFP91, TSLP, STAT4, SPRY1, EP300, IL10RB, } \\
\text { IL5RA, MPL, PIK3R3, PIK3R1 }\end{array}$ \\
\hline 7 & hsa04510:focal adhesion & 25 & $\begin{array}{c}\text { PDGFB, XIAP, PDGFA, COL2A1, ITGB1, CTNNB1, MYL9, } \\
\text { VCL, PTK2, PAK2, PAK4, COL6A2, PDGFC, PIK3R3, PIK3R1, } \\
\text { EGFR, TNXA, BAD, VWF, JUN, ITGA7, VEGFA, PDGFRB, } \\
\text { COL1A1, CRK }\end{array}$ \\
\hline 8 & $\begin{array}{l}\text { hsa04520:adherens } \\
\text { junction }\end{array}$ & 12 & $\begin{array}{l}\text { MAP3K7, EGFR, PTPN6, PVRL4, EP300, PVRL1, BAIAP2, } \\
\text { PVRL2, CTNND1, WAS, CTNNB1, VCL }\end{array}$ \\
\hline 9 & $\begin{array}{l}\text { hsa04810:regulation of } \\
\text { actin cytoskeleton }\end{array}$ & 23 & $\begin{array}{l}\text { EGFR, FGFR4, PDGFB, LIMK2, PDGFA, BAIAP2, ITGB1, } \\
\text { WAS, MYL9, TTLL3, VCL, PTK2, ARPC3, PAK2, GSN, CFL2, } \\
\text { PAK4, ITGA7, PDGFRB, PDGFC, PIK3R3, CRK, PIK3R1 }\end{array}$ \\
\hline 10 & $\begin{array}{l}\text { hsa05130:pathogenic } \\
\text { Escherichia coli infection }\end{array}$ & 9 & $\begin{array}{l}\text { NCK2, YWHAZ, KRT18, ARPC3, LOC399942, WAS, ITGB1, } \\
\text { CTNNB1, TTLL3 }\end{array}$ \\
\hline 11 & $\begin{array}{l}\text { hsa04115:p53 signaling } \\
\text { pathway }\end{array}$ & 10 & $\begin{array}{l}\text { CDKN1A, CDKN2A, ZMAT3, BAI1, RPRM, TP53, CHEK2, } \\
\text { GADD45B, CCNG2, GADD45A }\end{array}$ \\
\hline 12 & hsa04210:apoptosis & 14 & $\begin{array}{l}\text { XIAP, AIFM1, RELA, TP53, NFKBIA, BAD, BCL2L1, IRAK3, } \\
\text { CASP6, TNFSF10, IL1RAP, PRKACB, PIK3R3, PIK3R1 }\end{array}$ \\
\hline 13 & $\begin{array}{l}\text { hsa04150:mTOR signaling } \\
\text { pathway }\end{array}$ & 8 & $\begin{array}{l}\text { CAB39L, EIF4E, TSC1, STK11, VEGFA, PIK3R3, PIK3R1, } \\
\text { DDIT4 }\end{array}$ \\
\hline
\end{tabular}

also been reported to induce apoptosis in human chorionic villi [30].

\section{Conclusion}

E. faecalis infection induces stress and stimulus response activation, apoptosis, immune response disorder, and cell adhesion in human placental trophoblasts. It is likely that these effects may combine to damage placental trophoblasts, potentially leading to placental insufficiency and retardation of embryonic development. Therefore, this study provides important results on biological pathways that could potentially be targeted to develop interventions for the prevention/treatment of maternofetal infections caused by pathogenic enterococci.

\section{Conflicts of Interest}

The authors declare that they have no conflicts of interest.

\section{Acknowledgments}

This research project was supported by the National Natural Science Foundation of China (NSF31570075, 31170091, 31000048), Academic and Technical Leaders Training Program for Major Subjects of Jiangxi Province (2009), Research Program of the State Key Laboratory of Food Science and Technology of Nanchang University (SKLF-MB-201002), Foundation for Program of Department of Education from Fujian Province (JA15813), and Research Program of Xiamen Medical College (K2015-07). 
TABLE 3: Primers used for real-time PCR gene expression assays.

\begin{tabular}{|c|c|}
\hline Target gene & Sequence $\left(5^{\prime}-3^{\prime}\right)$ \\
\hline \multirow{2}{*}{ IL1 } & ACCTTCAAGGAGAGCATGGTG \\
\hline & GGTGCTGACCTAGGCTTGATG \\
\hline \multirow{2}{*}{ IL4 } & GCTATGACTAAAGCAGGGACAA \\
\hline & САСТCTCCTCAGCAAACACAGA \\
\hline \multirow{2}{*}{ IL6 } & TGCTCCTGGTGTTGCCTG \\
\hline & GCCGTCGAGGATGTACCG \\
\hline \multirow{2}{*}{ IL8 } & GGCTCTCTTGGCAGCCTTC \\
\hline & GCAGTTGGTCCACTCTCAATC \\
\hline \multirow{2}{*}{ IL10 } & CCAGGCAACCTGCCTAACA \\
\hline & TCTCAGACAAGGCTTGGCAAC \\
\hline \multirow{2}{*}{ IL12 } & GTCCTCCTGGACCACCTCAG \\
\hline & TCAATCTCTTCAGAAGTGCAAGG \\
\hline \multirow{2}{*}{ TNF- $\alpha$} & CACCACGCTCTTCTGCCTG \\
\hline & GTTCAGCCACTGGAGCTGC \\
\hline \multirow{2}{*}{ IFN- $\gamma$} & GCAGGTCATTCAGATGTAGCG \\
\hline & TTCCTTGATGGTCTCCACACTC \\
\hline \multirow{2}{*}{ TLR1 } & CAGTGTCTGGTACACGCATGGT \\
\hline & TTTCAAAAACCGTGTCTGTTAGAGA \\
\hline \multirow{2}{*}{ TLR2 } & CACTCAGGAGCAGCAAGCAC \\
\hline & GCAGGAACAGAGCACAGCAC \\
\hline \multirow{2}{*}{ TLR3 } & CCTGGTTTGTTAATTGGATTAACGA \\
\hline & TGAGGTGGAGTGTTGCAAAGG \\
\hline \multirow{2}{*}{ TLR4 } & CAGAGTTTCCTGCAATGGATCA \\
\hline & GCTTATCTGAAGGTGTTGCACAT \\
\hline \multirow{2}{*}{ TLR6 } & GAAGAAGAACAACCCTTTAGGATAGC \\
\hline & AGGCCAAACAAAATGGAAGCTT \\
\hline \multirow{2}{*}{ Claudin 1} & TGCTGGAATTGAACTACTCCAC \\
\hline & TACTCTTTCCGGTTGGTGTGA \\
\hline \multirow{2}{*}{ E-cadherin } & GAATGATGATGGTGGACAAT \\
\hline & TACCACATTCGTCACTGCTA \\
\hline \multirow{2}{*}{ Occludin } & GGCACСТGCATACTCACСС \\
\hline & CTGGGAGAGCAACTCATCCTC \\
\hline \multirow{2}{*}{$\mathrm{ZO}-1$} & CAACATACAGTGACGCTTCACA \\
\hline & CACTATTGACGTTTCCCCACTC \\
\hline \multirow{2}{*}{ ICAM } & TTGTCCTGCCAGCGACTC \\
\hline & AAGGAGTCGTGCCATAGGTG \\
\hline \multirow{2}{*}{ madCAM } & GCAGGAGGAGGAGGAGGAGGAG \\
\hline & TCCAAGCCAGGCAGCC \\
\hline \multirow{2}{*}{$\begin{array}{l}\beta \text {-2-microglobulin } \\
\text { (housekeeping gene) }\end{array}$} & GGCTATCCAGCGTACTCCAAA \\
\hline & CGGCAGGCATACTCATCTTTTT \\
\hline
\end{tabular}

\section{Supplementary Materials}

Table S1: differential gene expression profile of BeWo cell in response to Enterococcus faecalis OG1RF invasion. Table S2: differentially expressed genes classified with biological process in GO database. Table S3: differentially expressed genes classified with cellular component in GO database.
Table S4: differentially expressed genes classified with molecular function in GO database. Table S5: differentially expressed genes, containing representative terms of GO biological process category. Table S6: differentially expressed genes classified into different signal pathway of KEGG database. (Supplementary Materials) 


\section{References}

[1] Z. Peng, V. Krey, H. Wei et al., "Impact of actin on adhesion and translocation of Enterococcus faecalis," Archives of Microbiology, vol. 196, no. 2, pp. 109-117, 2014.

[2] K. L. Mason, T. A. Stepien, J. E. Blum et al., "From commensal to pathogen: translocation of Enterococcus faecalis from the midgut to the hemocoel of Manduca sexta," mBio, vol. 2, no. 3, pp. e00065-e00011, 2011.

[3] K. Shigematsu, M. Kogiso, M. Kobayashi, D. N. Herndon, and F. Suzuki, "Effect of CCL2 antisense oligodeoxynucleotides on bacterial translocation and subsequent sepsis in severely burned mice orally infected with Enterococcus faecalis," European Journal of Immunology, vol. 42, no. 1, pp. 158-164, 2012.

[4] K. Shigematsu, A. Asai, M. Kobayashi, D. N. Herndon, and F. Suzuki, "Enterococcus faecalis translocation in mice with severe burn injury: A pathogenic role of CCL2 and alternatively activated macrophages ( $\mathrm{M} 2 \mathrm{aM} \varphi$ and $\mathrm{M} 2 \mathrm{cM} \varphi)$," Journal of Leukocyte Biology, vol. 86, no. 4, pp. 999-1005, 2009.

[5] N. Steck, M. Hoffmann, I. G. Sava et al., "Enterococcus faecalis metalloprotease compromises epithelial barrier and contributes to intestinal inflammation," Gastroenterology, vol. 141, no. 3, pp. 959-971, 2011.

[6] Q. Tan, H. Xu, F. Xu et al., "Survival, distribution, and translocation of Enterococcus faecalis and implications for pregnant mice," FEMS Microbiology Letters, vol. 349, no. 1, pp. 32-39, 2013.

[7] J.-M. Choi and G.-J. Woo, "Transfer of Tetracycline Resistance Genes with Aggregation Substance in Food-Borne Enterococcus faecalis," Current Microbiology, vol. 70, no. 4, pp. 476-484, 2015.

[8] J.-H. Lee, D. Shin, B. Lee, H. Lee, I. Lee, and D.-W. Jeong, "Genetic diversity and antibiotic resistance of enterococcus faecalis isolates from traditional Korean fermented soybean foods," Journal of Microbiology and Biotechnology, vol. 27, no. 5, pp. 916-924, 2017.

[9] B. Fan, L. C. Carvalhais, A. Becker, D. Fedoseyenko, N. Von Wirén, and R. Borriss, "Transcriptomic profiling of Bacillus amyloliquefaciens FZB42 in response to maize root exudates," BMC Microbiology, vol. 12, article no. 116, 2012.

[10] A.-D. C. Chessler, M. Unnikrishnan, A. K. Bei, J. P. Daily, and B. A. Burleigh, "Trypanosoma cruzi triggers an early type I IFN response in vivo at the site of intradermal infection," The Journal of Immunology, vol. 182, no. 4, pp. 2288-2296, 2009.

[11] M. Rothbauer, N. Patel, H. Gondola, M. Siwetz, B. Huppertz, and P. Ertl, "A comparative study of five physiological key parameters between four different human trophoblast-derived cell lines," Scientific Reports, vol. 7, no. 1, article no. 5892, 2017.

[12] S. Correia Carreira, L. Walker, K. Paul, and M. Saunders, “The toxicity, transport and uptake of nanoparticles in the in vitro BeWo b30 placental cell barrier model used within NanoTEST," Nanotoxicology, vol. 9, no. 1, pp. 66-78, 2015.

[13] N. A. Albekairi, S. Al-Enazy, S. Ali, and E. Rytting, "Transport of digoxin-loaded polymeric nanoparticles across BeWo cells, an in vitro model of human placental trophoblast," Therapeutic Delivery, vol. 6, no. 12, pp. 1325-1334, 2015.

[14] M. Yasuda, S. Nagata, S. Yamane et al., "Pseudomonas aeruginosa serA gene is required for bacterial translocation through Caco-2 cell monolayers," PLoS ONE, vol. 12, no. 1, Article ID e0169367, 2017.

[15] O. Disson, S. Grayo, E. Huillet et al., "Conjugated action of two species-specific invasion proteins for fetoplacental listeriosis," Nature, vol. 455, no. 7216, pp. 1114-1118, 2008.
[16] M. Zheng, J. Wang, L. Ling, D. Xue, S. Wang, and Y. Zhao, "Screening and analysis of breast cancer genes regulated by the human mammary microenvironment in a humanized mouse model," Oncology Letters, vol. 12, no. 6, pp. 5261-5268, 2016.

[17] C. Y. Logan and R. Nusse, "The Wnt signaling pathway in development and disease," Annual Review of Cell and Developmental Biology, vol. 20, pp. 781-810, 2004.

[18] J. M. Kyriakis and J. Avruch, "Mammalian MAPK signal transduction pathways activated by stress and inflammation: a 10 -year update," Physiological Reviews, vol. 92, no. 2, pp. 689$737,2012$.

[19] S. Tripathy, R. Sen, S. K. Padhi et al., "Survey of the transcriptome of Brevibacillus borstelensis exposed to low temperature shock," Gene, vol. 550, no. 2, pp. 207-213, 2014.

[20] A. Klaus and W. Birchmeier, "Wnt signalling and its impact on development and cancer," Nature Reviews Cancer, vol. 8, no. 5, pp. 387-398, 2008.

[21] Y. Li, Y. Shibata, L. Zhang, N. Kuboyama, and Y. Abiko, "Periodontal pathogen Aggregatibacter actinomycetemcomitans LPS induces mitochondria-dependent-apoptosis in human placental trophoblasts," Placenta, vol. 32, no. 1, pp. 11-19, 2011.

[22] A. Hartsock and W. J. Nelson, "Adherens and tight junctions: structure, function and connections to the actin cytoskeleton," Biochimica et Biophysica Acta (BBA) - Biomembranes, vol. 1778, no. 3, pp. 660-669, 2008.

[23] C.-M. Chen, K.-N. Tsai, E.-C. Chan et al., "Cytotoxic effect of recombinant mycobacterium tuberculosis CFP-10/ESAT-6 protein on the crucial pathways of WI-38 cells," Journal of Biomedicine and Biotechnology, vol. 2009, Article ID 917084, 2009.

[24] M. Lecuit, D. M. Nelson, S. D. Smith et al., "Targeting and crossing of the human maternofetal barrier by Listeria monocytogenes: Role of internalin interaction with trophoblast Ecadherin," Proceedings of the National Acadamy of Sciences of the United States of America, vol. 101, no. 16, pp. 6152-6157, 2004.

[25] G. Nikitas, C. Deschamps, O. Disson, T. Niault, P. Cossart, and M. Lecuit, "Transcytosis of Listeria monocytogenes across the intestinal barrier upon specific targeting of goblet cell accessible E-cadherin," The Journal of Experimental Medicine, vol. 208, no. 11, pp. 2263-2277, 2011.

[26] P. Cossart and D. J. V. David, "Recent advances in understanding Listeria monocytogenes infection: The importance of subcellular and physiological context," F1000Research, vol. 6, article no. 1126, 2017.

[27] G. Mor and I. Cardenas, "The immune system in pregnancy: a unique complexity," American Journal of Reproductive Immunology, vol. 63, no. 6, pp. 425-433, 2010.

[28] J. R. Robbins and A. I. Bakardjiev, "Pathogens and the placental fortress," Current Opinion in Microbiology, vol. 15, no. 1, pp. 3643, 2012.

[29] N. Ishihara, H. Matsuo, H. Murakoshi, J. B. Laoag-Fernandez, T. Samoto, and T. Maruo, "Increased apoptosis in the syncytiotrophoblast in human term placentas complicated by either preeclampsia or intrauterine growth retardation," American Journal of Obstetrics \& Gynecology, vol. 186, no. 1, pp. 158-166, 2002.

[30] J. Duaso, G. Rojo, F. Jaña et al., "Trypanosoma cruzi induces apoptosis in ex vivo infected human chorionic villi," Placenta, vol. 32, no. 5, pp. 356-361, 2011. 


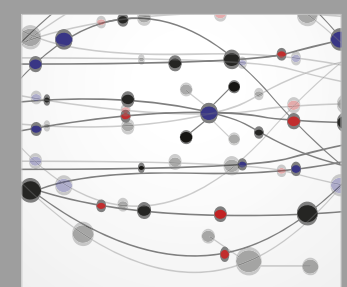

The Scientific World Journal
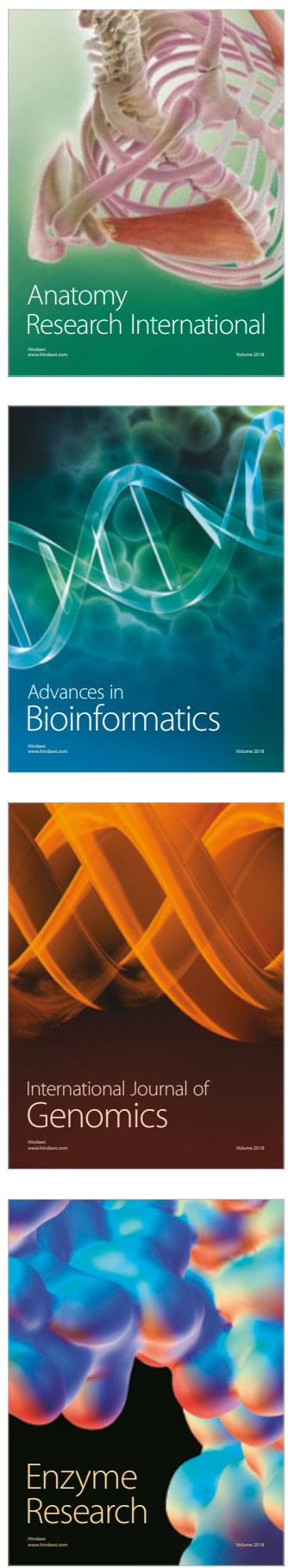
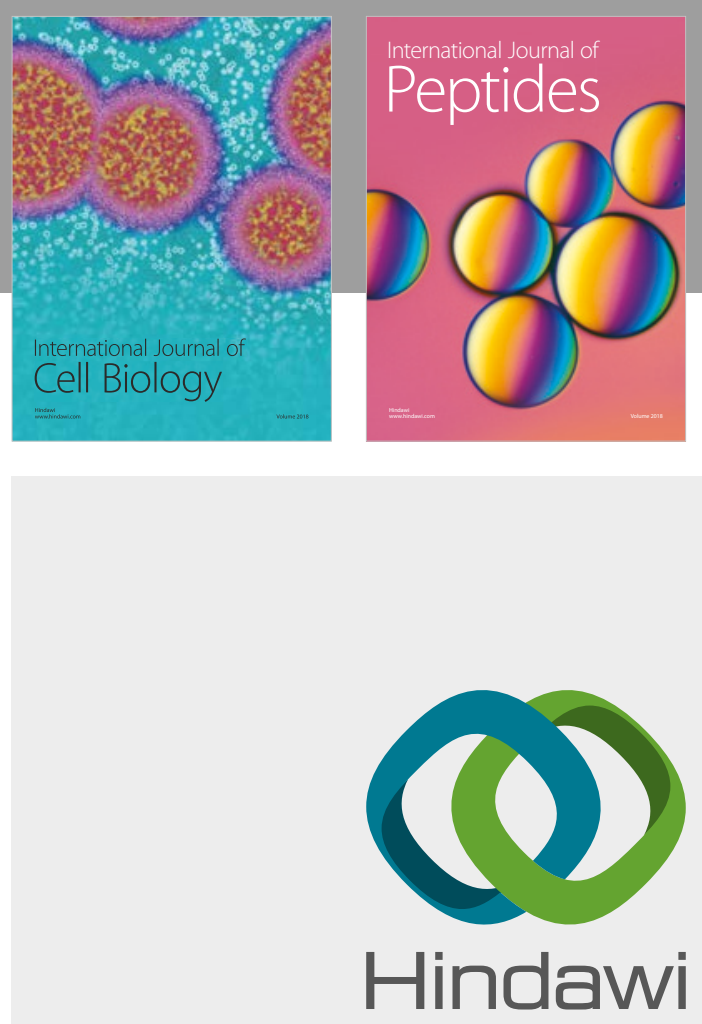

Submit your manuscripts at

www.hindawi.com
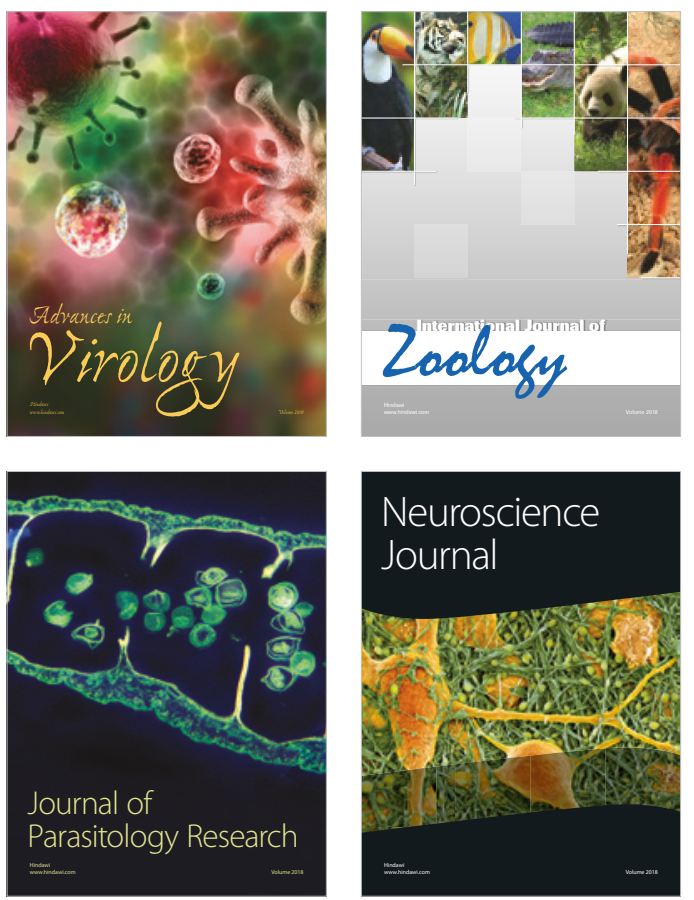
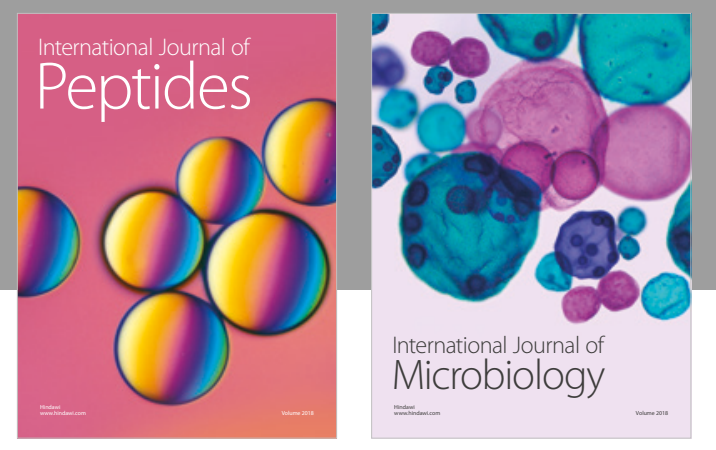

nternational Journal of Microbiology
Journal of
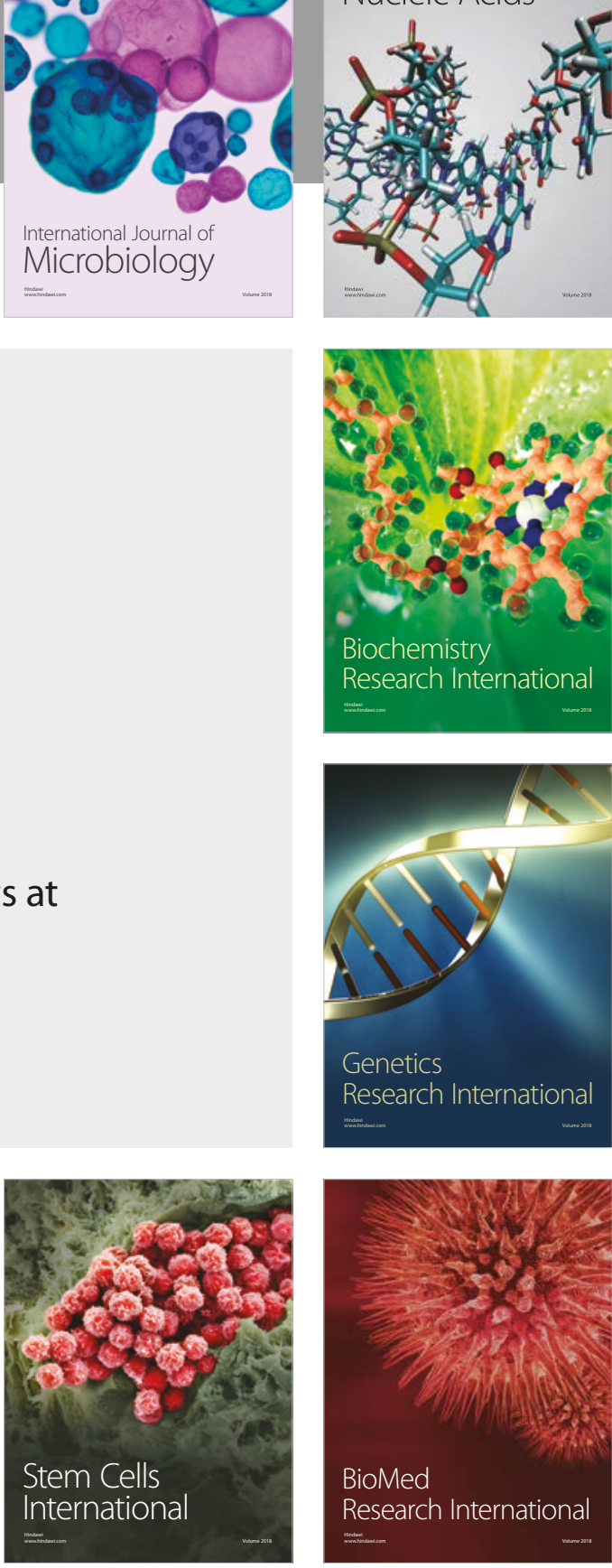
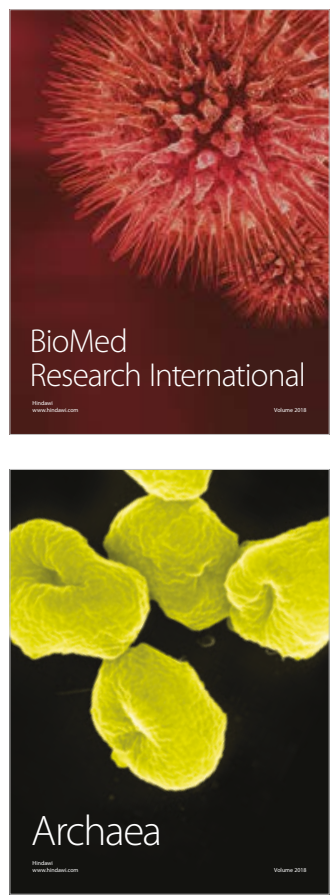